\title{
Comparative histological and ultrastructural studies on the liver and pancreas of Schilbe mystus and Labeo niloticus
}

\author{
Suzan, A. Naguib; William, Rizkalla and Fawzia, A. Abd El Ghafar \\ Department of Zoology, Faculty of Science, Ain Shams University, Egypt.
}

\begin{abstract}
$\mathrm{T}$ he present investigation aims to illustrate the histological and ultrastructural differences of the liver and pancreas of a carnivorous fish, Schilbe mystus, and a herbivorous fish, Labeo niloticus. The histological examination of the liver of both studied species revealed that the liver is mainly composed of a continuous compact field of the hepatocytes. The hepatocyte-sinusoidal structure of the liver of Schilbe mystus consists of the solid form and tubular one, while that of Labeo niloticus consists of the tubular form and cord-like one.

The ultrastructural examination of the liver of both studied species revealed that it is composed mainly of hepatocytes, Kupffer (macrophages) and to (fat-storing) cells. The hepatocytes of Schilbe mystus are characterized by the presence of numerous glycogen rosettes, numerous lipid droplets and a rough endoplasmic reticulum, while those of Labeo niloticus are characterized by the presence of numerous glycogen rosettes, a few lipid droplets and a rough endoplasmic reticulum. The hepatocytes of both studied species possess numerous microvilli, which extend into the space of Disse or into the bile canaliculi lumina.

In both studied species, there is a prominent perisinusoidal space between the hepatocytes and blood sinusoids, the space of Disse. This space usually contains the Ito cells, which are stellate in shape and are characterized by the presence of lipid droplets.

The bile canaliculi of Schilbe mystus are of the intercellular type, while those of Labeo niloticus are of both the intercellular and intracellular types.

The histological investigation of the pancreas of both studied species revealed that there are three types: the compact, disseminated and intrahepatic types. This pancreas showed that it consists of a highly lobulated gland of the compound acinar type. The acinar (pancreatic) cells are pyramidal in shape; they possess a basophilic cytoplasm and eosinophilic zymogenous secretory granules.

The ultrastructural investigation of the acinar cells of both studied species revealed two cell types: the dark and light acinar cells. These cells are characterized by the presence of numerous zymogenous secretory granules and a well-developed rough endoplasmic reticulum.
\end{abstract}

Key words: Schilbe mystus, Labeo niloticus, ultrastructural, liver, pancreas, histology 


\section{INTRODUCTION}

Al-Hussaini and Rizkalla (1958) stated that the zymogenous tissue of the pancreas of Tilapia nilotica is abundantly scattered in the adipose tissue, where it forms patches and rarely acini.

Rizkalla (1967) and Kamel et al. (1973) reported that the pancreas of Clarias lazera and Chrysichthys auratus, respectively, consists of three portions: compact, disseminated and intrahepatic. They also stated that the compact pancreas is located in the duodeno-hepatic mesentery, while the disseminated pancreatic patches accompany the branches of the hepatic portal vein in the mesenteries. On the other hand, the pancreas of the pike, Esox lucius, is a diffused tissue (Bucke, 1971), while that of Chalcalburnus tarichi is a separated organ (Ünal et al., 2001).

Peute et al. (1978) and Eastman \& DeVries (1981) stated that the hepatocytes of Brachydanio rerio and Dissostichus mawsoni, respectively, unusually contain a relatively small amount of glycogen and sometimes a large amount of lipid. Moreover, González et al. (1993) stated that the classical feature of the hepatocytes of various fish is the high content of glycogen that fills most of the cytoplasm.

Rizkalla and Emsheri (1978) stated that the pancreas of Lithognathus mormyrus consists of the disseminated and intrahepatic types and the zymogenous tissue, generally, tends to surround the endocrine one. In addition, they believed that the acini composing the zymogenous tissue are closely packed together with no constant shape.

Tanuma (1980) noticed that there are no interhepatocytic bile canaliculi in the liver parenchyma of the crucian, Carassius carassius, but each hepatocyte possesses a single intracellular bile canaliculus filled with microvilli protruded from the hepatocyte.

Eastman and DeVries (1981) stated that the liver of Dissostichus mawsoni is distinguished by many perisinusoidal (Ito) cells, which are adjacent to the perisinusoidal space. These cells are stellate in shape with long cytoplasmic arms and contain many large lipid droplets and numerous mitochondria. They also added that the livers of Pagothenia borchgrevinki, Trematomus bernacchii and Gymnodraco acuticeps, have a few number of the perisinusoidal cells that contain very few lipid droplets.

Ferri and Sesso (1981) reported that the liver of Pimelodus maculates has polymorphic Kupffer cells, which contain vacuoles varying widely in diameter, density and shape. They also suggested that these Kupffer cells and the endothelial cells may represent two different functional states of the same cell type.

Bodammer and Murchelano (1990) stated that the histological organization of the liver in the winter flounder, Pseudopleuronectes americanus, is characterized by the tubulo-sinusoidal structure and lacks the lobular configuration observed in mammals. They also added that the hepatocytes 
normally appear finely vacuolated because they contain lipid and glycogen reserves. They also stated that the plasma membrane of the hepatocyte facing the sinusoids has a microvillous border that extends into the perisinusoidal space of Disse.

Rocha et al. (1994) pointed out that no classical Kupffer cells are apparent in the liver of the brown trout, Salmo trutta fario, and the majority of the macrophages have interhepatic location and most frequently are in contact with the space of Disse.

Akiyoshi and Inoue (2004) found that the liver of the teleost fish is mainly composed of a continuous compact field of hepatocytes and scattered islands of connective tissue enclosing the bile ducts and arterial vessels. They also classified the hepatocyte- sinusoidal structures into three different types, the cord-like, tubular and solid forms.

Vicentini et al. (2005) reported that the liver of Oreochromis niloticus is made of hepatocytes spread out as anastomotic cords arranged in two cellular layers and surrounded by sinusoids. The bile ducts are usually found near the portal vein. They also stated that the intrahepatic exocrine pancreatic tissue is characterized by its acinar arrangement and it is separated from the hepatic cords by means of thin connective tissue septa. They also demonstrated that the exocrine cells are ultrastructurally differentiated from the other cellular types by the presence of zymogenous granules and a well developed rough endoplasmic reticulum.

Figueiredo-Fernandes et al. (2007) stated that the hepatocytes of Oreochromis niloticus form a continuous cell mass, tunnelled by sinusoids, resulting in a meshwork of two or more cell-thick plates. In addition, the traditional lobulation, as reported in the mammalian liver, is not discernible.

Giari et al. (2008) stated that the hepatocytes of Dicentrarchus labrax are characterized by a well-developed rough endoplasmic reticulum, abundant glycogen particles and a few lipid droplets.

Gilloteaux et al. (2008) stated that the pancreatic acinar cells of Scorpaena scrofa possess extraordinary abundance of rough endoplasmic reticulum, which is made up of narrow and wide tubular cisternae as well as a network.

\section{MATERIALS AND METHODS}

The freshwater Nile silver schilbid catfish, Schilbe mystus (Linnaeus, 1758), (Order: Siluriformes, Family: Schilbeidae) and the freshwater Nile carp, Labeo niloticus (Forsskål, 1775), (Order: Cypriniformes, Family: Cyprinidae) were used in the present investigation.

\section{1- Collection of the Samples:}

The adult specimens of the silver schilbid catfish, Schilbe mystus, ranging from $15-28 \mathrm{~cm}$ in length, and of the Nile carp, Labeo niloticus, ranging from 20 $40 \mathrm{~cm}$ in length, were caught alive from the River Nile at different localities 
between Beni Suef and Giza. They were killed and dissected immediately in the field.

\section{2- Histological and Ultrastructural Studies:}

Fresh adult specimens were carefully dissected and small pieces of the liver and pancreas of both studied species were fixed in aqueous Bouin's fluid. Sections of 5-7 $\mu \mathrm{m}$ thick were cut and stained with Harris' haematoxylin and counterstained with eosin.

Small pieces of the liver and pancreas of both studied species were immediately fixed in cold 3\% glutaraldehyde solution in phosphate buffer ( $\mathrm{pH}$ 7.2 to 7.4) or in a mixture of glutaraldehyde and formaldehyde for three hours to overnight at $4^{\circ} \mathrm{C}$, then immersed in the phosphate buffer for $24 \mathrm{hrs}$.

Resin blocks were cut with the ultramicrotome into semithin sections ( $1 \mu \mathrm{m}$ thick) and stained with toluidine blue. The slides were examined with the light microscope to select the suitable areas for ultrathin sectioning. Silver to pale golden ultrathin sections ( $600 \AA$ in thickness) were mounted on copper grids. The sections were stained in darkness with $5 \%$ uranyle acetate and lead citrate according to Reynolds (1963). Finally, the grids were then examined with JOEL 1200 EX II electron microscope at the Electron Microscope Unit in the Central Laboratory, Faculty of Science, Ain Shams University and JOEL 100S electron microscope at the Electron Microscope Unit in the National Cancer Institute.

\section{A-The liver}

\section{RESULTS}

\section{1- Histological Studies}

The liver of both studied species is mainly composed of a continuous compact field of the hepatocytes and scattered islands of connective tissue that enclose the bile ductules and blood vessels. The hepatic lobular structure, which characterizes the mammalian liver, is totally absent.

\section{a- Schilbe mystus:}

The hepatocyte-sinusoidal structure of the liver of Schilbe mystus consists of two forms: the solid form (Fig. 1), and the tubular one (Fig. 2). In the solid form of the hepatocyte-sinusoidal structure, the sinusoids are narrow and surrounded by multilayer of the hepatocytes (Fig. 1). On the other hand, in the tubular form of the hepatocyte-sinusoidal structure the sinusoids are wide and irregular; they are surrounded by double layers of the hepatocytes (Fig. 2).

The hepatocytes are polygonal in shape with a homogeneous eosinophilic finely granulated cytoplasm, which contains numerous fat droplets. The nuclei of the hepatocytes are large, rounded with prominent nucleoli. The nuclei of the hepatocytes are eccentrically located due to the presence of fat vacuolizations (Fig. 3).

The central vein and the blood sinusoids are lined by flattened endothelial cells with a homogeneous attenuated cytoplasm and flattened darkly stained nuclei (Fig. 2). 
The bile, which is secreted by the hepatocytes, drains into a system of bile collecting ductules of variable sizes. The bile collecting system starts as very small ductules, then become larger ones. They are lined by simple cuboidal epithelial cells with a homogeneous eosinophilic cytoplasm and rounded centrally located nuclei. These bile ductules are surrounded by a layer of compact connective tissue of variable thickness (Fig. 4).

\section{b- Labeo niloticus:}

The hepatocyte-sinusoidal structure of the liver of Labeo niloticus consists of two forms: the tubular form (Fig. 5), and cord-like form (Fig. 6). The tubular form of the hepatocyte-sinusoidal structure is similar to that of Schilbe mystus (Fig. 5). On the other hand, the cord-like form of the hepatocyte-sinusoidal structure has wide and straight sinusoids, which are surrounded by a single layer of the hepatocytes (Fig. 6). The structural features of the hepatocytes are similar to those of Schilbe mystus (Figs. 5 and 6).

The Ito cells, which are fat storage cells, are located in the perisinusoidal spaces, between the sinusoids and the hepatocytes. The Ito cells are rounded in shape and possess numerous vacuoles in their cytoplasm. The nuclei of the Ito cells are rounded, centrally located and with prominent nucleoli (Fig. 5).

The central vein and the blood sinusoids are lined by the endothelial cells, which are similar to those of Schilbe mystus (Figs. 5 and 6).

The bile ductules are small and their structure simulates that of Schilbe mystus (Fig. 6).

\section{2- Ultrastructural Studies a- Schilbe mystus:}

The liver of Schilbe mystus is composed of a large population of hepatocytes, few Kupffer cells and numerous Ito cells. The hepatocytes are usually differentiated into numerous electron-lucent light hepatocytes, with wide tubules and cisternae of rough endoplasmic reticulum, and a few numbers of electron-dense dark hepatocytes with narrow tubules of rough endoplasmic reticulum (Fig. 7).

The hepatocytes are cuboidal in shape, and each hepatocyte possesses a single oval or rounded nucleus with a prominent nucleolus. The chromatin is differentiated into two types: the euchromatin and heterochromatin. The euchromatin is represented by the pale granular areas, while the heterochromatin consists of condensed dark clumps in the nucleoplasm and at the nuclear periphery (Fig. 7).

The cytoplasm of the hepatocytes is characterized by the presence of numerous glycogen particles, as glycogen rosettes, and large lipid droplets (the mean diameter is about $4.5 \mu \mathrm{m}$ ) (Fig. 7).

The cytoplasm of the hepatocytes is characterized by the presence of a well developed rough endoplasmic reticulum, which consists of parallel tubules or cisternae that are studded with numerous ribosomes (Fig. 8). On the other hand, the smooth endoplasmic reticulum is poorly developed. 
The mitochondria are numerous, electron-dense, polymorphic (rounded, oval and elongated in shape) and with variable sizes (the mean diameter is about $0.3 \mu \mathrm{m}$ and the mean long axis is about $0.8 \mu \mathrm{m})$. The mitochondria are scattered throughout the hepatocyte cytoplasm (Figs. 7 and 8). The inner mitochondrial membrane forms lamellar cristae (Fig. 8).

The cell membranes of the hepatocytes facing the sinusoids usually bear numerous interlocked microvilli, which extend into the perisinusoidal space, the space of Disse (Fig. 9).

The bile canaliculi are represented by the intercellular bile canaliculi, which are formed by the apposition of 3 to 5 hepatocytes. Numerous microvilli project from the hepatocyte cell membranes into the lumina of the intercellular canaliculi (Fig. 10).

The Kupffer, or stellate cells (macrophages) are found on the luminal surface of the endothelial cells and project into the sinusoidal lumen. These cells are stellate in shape and each one possesses an oval or indented heterochromatic nucleus. The cytoplasm of the Kupffer cell possesses few scattered mitochondria, vesicles and the most distinctive cellular structure, the lysosomes.

The cell membrane of the free surface facing the sinusoidal lumen is thrown up into microvilli-like projections. Moreover, the cell membrane at the contact with the endothelial cells is linked by spot desmosomes (Fig. 9).

The liver of Schilbe mystus is characterized by the presence of numerous Ito (fat-storing) cells. The Ito cells have more electron-dense figures, as compared with those of the hepatocytes, and are located adjacent to the space of Disse as well as between the hepatocytes. The Ito cell is stellate in shape; it possesses flattened cytoplasmic processes and numerous large lipid droplets. The nuclei of the Ito cells are more darkly stained than those of the hepatocytes and each one possesses a prominent nucleolus. These cells possess an extensive rough endoplasmic reticulum and numerous mitochondria (Fig. 11).

\section{b- Labeo niloticus:}

The liver of Labeo niloticus is composed of a large population of hepatocytes, numerous Kupffer cells and Ito cells. The hepatocytes are cuboidal cells and each hepatocyte possesses a single oval or rounded euchromatic nucleus with a prominent nucleolus (Fig. 12).

The cytoplasm of the hepatocytes is characterized by the presence of numerous glycogen particles, as glycogen rosettes, and few small lipid droplets (the mean diameter is about $0.6 \mu \mathrm{m}$ ) (Fig. 12).

The cytoplasm of the hepatocytes is characterized by the presence of a well developed rough endoplasmic reticulum, which consists of parallel tubules that are studded with numerous ribosomes (Fig. 13). On the other hand, the smooth endoplasmic reticulum is poorly developed.

The mitochondria are numerous, electron-dense, polymorphic (rounded, oval and elongated in shape) and with variable sizes (the mean diameter is about $0.3 \mu \mathrm{m}$ and the mean long axis is about $0.7 \mu \mathrm{m}$ ). The mitochondria are scattered 
throughout the cytoplasm (Fig. 12). The inner mitochondrial membrane forms lamellar cristae (Fig. 13).

The cell membranes of the hepatocytes facing the sinusoids usually bear numerous microvilli, which extend into the wide perisinusoidal space, the space of Disse (Fig. 14).

The bile canaliculi are represented by two types: the intercellular and intracellular bile canaliculi. The intercellular bile canaliculi are similar to those what have been described for Schilbe mystus, whereas the intracellular bile canaliculi are formed of the invaginated cell membranes towards the nuclear area. Numerous microvilli project from the hepatocyte cell membranes into the lumina of the canaliculi (Fig. 15).

The structure of the Kupffer cells does not differ from that of Schilbe mystus (Fig. 16).

The liver of Labeo niloticus is characterized by the presence of the Ito (fat-storing) cells, which are located adjacent to the space of Disse as well as between the hepatocytes. The Ito cell is stellate in shape; it possesses flattened cytoplasmic processes, numerous lipid droplets and mitochondria. The Ito cell possesses a heterochromatic nucleus (Fig. 17).

\section{B-The pancreas}

\section{1- Histological Studies}

The pancreas of both studied species displays three types: the compact, disseminated and intrahepatic types.

\section{a- Schilbe mystus:}

The pancreas of Schilbe mystus is a highly lobulated gland of the compound acinar type. Each pancreatic lobule consists of closely packed secretory pancreatic acini separated by thin connective tissue septa (Fig. 18).

The cells of the pancreatic acini, the acinar or pancreatic cells, are pyramidal in shape. The apices of the acinar cells project towards a central lumen of a minute duct, which represents the terminal end of the pancreatic duct system. The apical cytoplasm of the acinar cells is crammed with the zymogenous secretory granules. The nuclei of the acinar cells are basally located and possess prominent centrally located nucleoli. The nuclei are surrounded by a basophilic cytoplasm (Fig. 18).

\section{b- Labeo niloticus:}

The pancreas of Labeo niloticus is a highly lobulated compound acinar gland. Each pancreatic lobule consists of closely packed secretory pancreatic acini, whose cells are structurally similar to those of Schilbe mystus (Fig. 19).

\section{2- Ultrastructural Studies} a- Schilbe mystus

The exocrine pancreas of Schilbe mystus is formed of acinar or pancreatic cells. These cells are pyramidal or prismatic in shape with broad bases and narrow apices, which line the narrow acinar lumen. According to the electron 
density, the acinar cells are differentiated into two types: the dark and light cells (Fig. 20).

The acinar cells are characterized by the presence of an extraordinary abundance of a well-developed rough endoplasmic reticulum and free ribosomes. The rough endoplasmic reticulum of the dark cells consists of long wide tubules and vesicles. On the other hand, the rough endoplasmic reticulum of the light cells consists of short tubules and vesicles, whose lumina appear clear (Fig. 20).

The secretory zymogenous granules are numerous and rounded in shape; they are scattered throughout the cell cytoplasm and are mainly concentrated in the apical region of the cell cytoplasm. These granules possess an electron-dense material, which is tightly bound by a membrane (Fig. 21). The sizes of these granules are variable with a mean diameter of about $1.5 \mu \mathrm{m}$.

The mitochondria are elongated or oval in shape and are scattered throughout the cell cytoplasm. The mitochondrial cristae are lamellar in shape (Fig. 20).

The nuclei of both dark and light acinar cells are rounded or oval in shape and are basally located. The nucleolus is prominent and centrally located. The chromatin consists of two types: the euchromatin and heterochromatin. The euchromatin is well developed and is represented by the electron-lucent granular areas, whereas the heterochromatin is represented by the small electron-dense granular areas dispersed in the nucleoplasm and attached to the inner side of the nuclear envelope (Fig. 21).

The pancreatic duct is lined by 2-3 cuboidal cells, which possess electronlucent figures. The desmosomes are found between the adjacent duct cells. The cytoplasm of the duct cell has a large, oval and basally located heterochromatic nucleus and scattered small mitochondria (Fig. 22).

\section{b- Labeo niloticus:}

The exocrine pancreas of Labeo niloticus is formed of acinar or pancreatic cells, which are differentiated into two types: the dark and light cells (Fig. 23).

The acinar cells are characterized by the presence of an extraordinary abundance of a well-developed rough endoplasmic reticulum and free ribosomes. The rough endoplasmic reticulum of the dark cells consists of narrow and long tubules and vesicles. On the other hand, the rough endoplasmic reticulum of the light cells consists of cisternae and vesicles whose lumina appear clear (Fig. 23).

The ultrastructral features of the secretory zymogenous granules are similar to those of Schilbe mystus. The zymogenous granules are excreted by the process of exocytosis through the apical cell membrane into the acinar lumen (Fig. 24). The lumina of the pancreatic ducts are also seen filled with the zymogenous secretion (Fig. 25).

The mitochondria are elongated or oval in shape and are scattered throughout the cell cytoplasm. The mitochondrial cristae are lamellar in shape 
(Fig. 23). The nuclei of both the dark and light acinar cells are rounded or oval in shape and are basally located. The ultrastructural features of these nuclei are similar to those of Schilbe mystus (Fig. 26).

The pancreatic duct is lined by $2-3$ cuboidal cells, which possess electronlucent figures. The ultrastructural characteristics of this duct simulate those of Schilbe mystus (Fig. 25).

\section{DISCUSSION}

The liver of both studied species is mainly composed of a continuous compact field of the eosinophilic polygonal hepatocytes and scattered islands of connective tissue that enclose the bile ductules and blood vessels. The hepatic lobular structure, which characterizes the mammalian liver, is totally absent. These results agree with those of Bodammer and Murchelano (1990), in Pseudopleuronectes americanus, Pack et al. (1996), in Brachydanio rerio, Akiyoshi and Inoue (2004), in two hundred teleost species, Rodríguez et al. (2005), in Anguilla anguilla, Vicentini et al. (2005) and Figueiredo-Fernandes et al. (2007), in Oreochromis niloticus.

The hepatocyte-sinusoidal structure of Schilbe mystus consists of two forms: the solid form and tubular one, whereas that of Labeo niloticus consists of two forms: the tubular form and cord-like one. The hepatocyte-sinusoidal structure is physiologically important because the hepatocytes exchange large molecules with the sinusoids. Akiyoshi and Inoue (2004) classified the hepatocyte-sinusoidal structure, in two hundred teleost species, into three forms: the cord-like form, tubular form and solid one. In addition, they stated that each teleost species possesses one or two forms of these previous hepatocytesinusoidal structures. Moreover, Bodammer and Murchelano (1990) and Vicentini et al. (2005) stated that the hepatocyte-sinusoidal structure of Pseudopleuronectes americanus and Oreochromis niloticus, respectively, is of the tubular form.

The hepatocytes of both studied species are characterized by the presence of numerous glycogen particles, as glycogen rosettes. This result agrees with that of Sylvie et al. (1996), in Oncorhynchus mykiss, Rodríguez et al. (2005), in Anguilla anguilla, and Giari et al. (2008), in Dicentrarchus labrax, but contradict with those of Eastman and DeVries (1981) and Rocha et al. (1994) who stated that the hepatocytes of Dissostichus mawsoni and Salmo trutta fario, respectively, possess a few glycogen particles.

The hepatocytes of the carnivorous Schilbe mystus possess numerous and large lipid droplets. This observation agrees with that of Eastman and DeVries (1981), in the carnivorous Dissostichus mawsoni, Rocha et al. (1994), in the carnivorous Salmo trutta fario, and Rodríguez et al. (2005), in the carnivorous Anguilla anguilla. On the other hand, the hepatocytes of Labeo niloticus possess a few and small lipid droplets. This observation agrees with that of Weis (1972), 
in Brachydanio rerio and Gambusia affinis, and Giari et al. (2008), in Dicentrarchus labrax.

The bile canaliculi of Schilbe mystus are represented by the intercellular bile canaliculi, whereas those of Labeo niloticus are represented by two types: the intercellular and intracellular bile canaliculi. Peute et al. (1978) stated that the two types of the bile canaliculi (the intercellular and intracellular) are found in the liver of the herbivorous Brachydanio rerio. Moreover, Tanuma (1980) stated that the liver of Carassius carassius possesses only the intracellular bile canaliculi, while Tanuma et al. (1982) stated that the liver of Kareius bicoloratus possesses only the intercellular bile canaliculi. In addition, Rocha et al. (1994) stated that the bile canaliculi of the liver of the carnivorous Salmo trutta fario are represented mainly by the intercellular type, while the intracellular type is very rare.

The Kupffer or stellate cells (macrophages) are found in both studied species; they are found in the sinusoidal endothelium and project into the sinusoidal lumen. The Kupffer and the sinusoidal endothelial cells are linked by the spot desmosomes to provide a strong attachment and prevent the Kupffer cells from being washed away by the blood. Ferri and Sesso (1981) also reported Kupffer cells in the liver of Pimelodus maculatus, but Tanuma et al. (1982) and Rocha et al. (1994) stated that no classical Kupffer cells are present in the liver of Kareius bicoloratus and Salmo trutta fario, respectively.

The Ito (fat-storing) cells of both studied species are located between the hepatocytes as well as adjacent to the perisinusoidal space of Disse. They are characterized by the presence of prominent lipid inclusions, an extensive rough endoplasmic reticulum and flattened cytoplasmic processes. These results agree with those of Nopanitaya et al. (1979), in five teleost species, Eastman and DeVries (1981), in Dissostichus mawsoni and Rocha et al. (1994), in Salmo trutta fario.

The pancreas of both studied species is represented by three types: the compact, disseminated and intrahepatic types. Similar types were reported in Clarias lazera (Rizkalla, 1967), Bagrus bayad (Rizkalla and Amer, 1972), Chrysichthys auratus (Kamel et al., 1973) and Chalcalburnus tarichi (Ünal et al., 2001). However, Eastman and DeVries (1997) stated that the nototheniid fishes lack the intrahepatic pancreas.

The pancreas of both studied species is a highly lobulated gland of the compound acinar type. Each pancreatic lobule consists of closely packed secretory pancreatic acini separated by scarce connective tissue. These results agree with those of Beccaria et al. (1992), in Dicentrarchus labrax, FigueiredoFernandes et al. (2007) in Oreochromis niloticus.

The acinar cells of both studied species are basophilic pyramidal cells, which are crammed with zymogenous secretory granules. These results agree with those described in Tilapia nilotica (Al-Hussaini and Rizkalla, 1958), Clarias lazera (Rizkalla, 1967), Bagrus bayad (Rizkalla and Amer, 1972), 
Lithognathus mormyrus (Rizkalla and Emsheri, 1978) and the nototheniid fishes (Eastman and DeVries, 1997).

The acinar cells of both studied species are characterized by the presence of the zymogenous secretory granules, an extraordinary abundance of a welldeveloped rough endoplasmic reticulum and free ribosomes. These results agree with those of Beccaria et al. (1992), in Dicentrarchus labrax, and Gilloteaux et al. (2008) in Scorpaena scrofa.

\section{REFERENCES}

Akiyoshi, H. and Inoue, A. (2004). Comparative histological study of teleost livers in relation of phylogeny. Zool. Sci., 21: 841-850.

Al-Hussaini, A.H. and Rizkalla, W. (1958). The pancreas and islets of Langerhans in the cichlid fish, Tilapia nilotica, L. Ain Shams Sci. Bull., 3: 165-196.

Beccaria, C.; Diaz, J. P. and Connes, R. (1992). Effects of dietary conditions on the exocrine pancreas of the sea bass, Dicentrarchus labrax L. (Teleostei). Aquaculture, 101: 163-176.

Bodammer, J.E. and Murchelano, R.A. (1990). Cytological study of vacuolated cells and other aberrant hepatocytes in winter flounder from Boston Harbor. Cancer Res., 50: 6744-6756.

Bucke, D. (1971). The anatomy and histology of the alimentary tract of the carnivorous fish the pike Esox lucius L., J. Fish Biol., 3: 421-431.

Eastman, J.T. and DeVries, A.L. (1981). Hepatic ultrastructural specialization in Antarctic fishes. Cell Tiss. Res., 219: 489-496.

Eastman, J.T. and DeVries, A.L. (1997). Morphology of the digestive system of Antarctic nototheniid fishes. Polar Biol., 17: 1-13.

Ferri, S. and Sesso, A. (1981). Ultrastructural study of Kupffer cells in teleost liver under normal and experimental conditions. Cell Tiss. Res., 220: 387-391.

Figueiredo-Fernandes, A. M.; Fontaínhas- Fernandes, A. A.; Monteiro, R.A.F.; Reis-Henriques, M. A. and Rocha, E. (2007). Spatial relationships of the intrahepatic vascular-biliary tracts and associated pancreatic acini of Nile tilapia, Oreochromis niloticus (Teleostei, Cichlidae): a serial section study by the light microscopy. Ann. Anat., 189: 17-30. 
Giari, L.; Simoni, E.; Manera, M. and Dezfuli, B.S. (2008). Histo-cytological responses of Dicentrarchus labrax (L.) following mercury exposure. Ecotoxicol. Environ. Safety, 70: 400-410.

Gilloteaux, J.; Kashouty, R. and Yono, N. (2008). The perinuclear space of pancreatic acinar cells and the synthetic pathway of zymogen in Scorpaena scrofa L.: ultrastructural aspects. Tiss. Cell, 40: 7-20.

González, G.; Crespo, S. and Bruslé, J. (1993). Histo-cytological study of the liver of the cabrilla sea bass, Serranus cabrilla (Teleostei, Serranidae), an available model for marine fish experimental studies. J. Fish Biol., 43: 363-373.

Kamel, A.; Rizkalla, W. and Shakhsheir, E. (1973). Studies on the pancreas of the Nile teleost fish, Chrysichthys auratus Geoffr., with special reference to the islet tissue. $7^{\text {th }}$ Arab Sci. Cong. Cairo, 4: 77-86.

Nopanitaya, W.; Aghajanian, J.; Grisham, J.W. and Carson, J.L. (1979). An ultrastructural study on a new type of hepatic perisinusoidal cell in fish. Cell Tiss. Res., 198: 35-42.

Pack, M.; Solnica-Krezel, L.; Malicki, J.; Neuhauss, S.C.F.; Schier, A.F.; Stemple, D.L.; Driever, W. and Fishman,M.C. (1996). Mutations affecting development of zebrafish digestive organs. Development, 123: 321-328.

Peute, J.; van der Gaag, M.A. and Lambert, J.G.D. (1978). ultrastructure and lipid content of the liver of the zebrafish, Brachydanio rerio, related to vitellogenin synthesis. Cell Tiss. Res., 186: 297-308.

Reynolds, E. S. (1963). The use of lead citrate at high $\mathrm{pH}$ as an electron opaque stain in electron microscopy. J. Cell Biol., 17: 208-212.

Rizkalla, W. (1967). The Pancreas and islets of Langerhans of the teleost, Clarias lazera, C. \& V. Proc. Zool. Soc. U.A.R., 2: 27-41.

Rizkalla, W. and Amer, F.I. (1972). Studies on the pancreatic islets of the Nile teleost Bagrus bajad. Proc. Zool. Soc. A.R.E., 4: 107-116.

Rizkalla, W. and Emsheri, O. (1978). The pancreas of the marine teleost fish, Lithognathus mormyrus L., with special reference to its islet tissue. The Libyan J. Sci., 8(A): 1-20. 
Rocha, E.; Monteiro, R.A.F. and Pereira, C.A. (1994). The liver of the brown trout, Salmo trutta fario: a light and electron microscope study. J. Anat., 185: 241-249.

Rodríguez, A.; Gisbert, E.; Rodríguez, G. and Castello-Orvay, F. (2005). Histopathological observations in European glass eels (Anguilla anguilla) reared under different diets and salinities. Aquaculture, 244: 203-214.

Sylvie, B.R.; Pairault, C.; Vernet, G. and Boulekbache, H. (1996). Effect of lindane on the ultrastructure of the liver of the rainbow trout, Oncorhynchus mykiss, sac-fry. Chemosphere, 33(10): 2065-2079.

Tanuma, Y. (1980). Electron microscope observations on the intrahepatocytic bile canalicules and sequent bile ductules in the crucian, Carassius carassius. Arch. Histol. Jpn., 43(1): 1-21.

Tanuma, Y.; Ohata, M. and Ito, T. (1982). Electron microscopic study on the sinusoidal wall of the liver in the flatfish, Kareius bicoloratus: demonstration of numerous desmosomes along the sinusoidal wall. Arch. Histol. Jpn., 45(5): 453-471.

Ünal, G.; Çetinkaya, O.; Kankaya, E. and Elp, M. (2001). Histological study of the organogenesis of the digestive system and swim bladder of the Chalcalburnus tarichi Pallas, 1811 (Cyprinidae). Turk. J. Zool., 25: 217228.

Vicentini, C.A.; Franceschini- Vicentini, I.B.; Bombonato, M.T.S.; Bertolucci, B.; Lima, S.G. and Santos,A.S. (2005). Morphological study of the liver in the teleost, Oreochromis niloticus. Int. J. Morphol., 23(3): 211-216.

Weis, P. (1972). Hepatic ultrastructure in two species of normal, fasted and gravid teleost fishes. Am. J. Anat., 133: 317-332. 


\section{EXPLANATION OF FIGURES}

Fig. (1): Photomicrograph of a section of the liver of Schilbe mystus showing the solid form of the hepatocyte-sinusoidal structure, hepatocytes and blood sinusoids. H \& E stain, X 525.

Fig. (2): Photomicrograph of a section of the liver of Schilbe mystus showing the tubular form of the hepatocyte-sinusoidal structure, hepatocytes and blood sinusoids. H \& E stain, X 525.

Fig. (3): Photomicrograph of a section of the liver of Schilbe mystus showing the hepatocytes and lipid droplets. H \& E stain, X 1500.

Fig. (4): Photomicrograph of a section of the liver of Schilbe mystus showing the hepatocytes, small bile ductule, with compact connective tissue, and blood sinusoids. H \& E stain, X 525.

Fig. (5): Photomicrograph of a section of the liver of Labeo niloticus showing the hepatocytes, scattered Ito cells, tubular form of the hepatocytesinusoidal structure, blood sinusoids and endothelial cells. H \& E stain, X 525 .

Fig. (6): Photomicrograph of a section of the liver of Labeo niloticus showing the hepatocytes, bile ductule, blood vessel, cord-like form of the hepatocyte-sinusoidal structure, blood sinusoids and endothelial cells. $\mathrm{H}$ \& E stain, X 525.

Fig. (7): Electron micrograph of the liver of Schilbe mystus showing the light and dark hepatocytes, nucleus, nucleolus, euchromatin, heterochromatin, glycogen rosettes, lipid droplets and mitochondria.

Fig. (8): Electron micrograph of the liver of Schilbe mystus showing the hepatocytes, rough endoplasmic reticulum and mitochondria.

Fig. (9): Electron micrograph of the liver of Schilbe mystus showing the space of Disse, microvilli of the hepatocyte, blood sinusoid, endothelial cell and Kupffer cell with projections (star), desmosomes (arrow heads), nucleus, mitochondria, vesicles and lysosomes.

Fig. (10): Electron micrograph of the liver of Schilbe mystus showing the intercellular bile canaliculus, hepatocytes and microvilli. 
Fig. (11): Electron micrograph of the liver of Schilbe mystus showing the Ito cell, lipid droplets, mitochondria and hepatocyte.

Fig. (12): Electron micrograph of the liver of Labeo niloticus showing the hepatocyte, nucleus, nucleolus, euchromatin, heterochromatin, glycogen rosettes, lipid droplets and mitochondria.

Fig. (13): Electron micrograph of the hepatocytes of Labeo niloticus showing the rough endoplasmic reticulum and mitochondria.

Fig. (14): Electron micrograph of the liver of Labeo niloticus showing the space of Disse, microvilli of the hepatocyte, blood sinusoid, endothelial cell.

Fig. (15): Electron micrograph of the liver of Labeo niloticus showing the intracellular bile canaliculi, hepatocytes, microvilli and space of Disse.

Fig. (16): Electron micrograph of the liver of Labeo niloticus showing the Kupffer cell, nucleus, vesicles, lysosomes, hepatocyte, blood sinusoid and space of Disse.

Fig. (17): Electron micrograph of the liver of Labeo niloticus showing the Ito cell, lipid droplets, nucleus, hepatocytes, space of Disse, blood sinusoid and endothelial cell.

Fig. (18): Photomicrograph of a section of the compact pancreas of Schilbe mystus showing the pancreatic acini, central lumen and the connective tissue septa. H \& E stain, X 525.

Fig. (19): Photomicrograph of a section of the pancreas of Labeo niloticus showing the acinar cells and zymogenous granules. H \& E stain, $\mathrm{X}$ 1270 .

Fig. (20): Electron micrograph of the pancreas of Schilbe mystus showing the light and dark acinar cells, rough endoplasmic reticulum and mitochondria.

Fig. (21): Electron micrograph of the acinar cells of Schilbe mystus showing the nucleus, nucleolus, euchromatin, heterochromatin and nuclear envelope.

Fig. (22): Electron micrograph of the pancreatic duct of Schilbe mystus showing the duct cells, nucleus, desmosomes, mitochondria and pancreatic duct lumen (arrow head). 
Fig. (23): Electron micrograph of the pancreas of Labeo niloticus showing the light and dark acinar cells, rough endoplasmic reticulum and mitochondria.

Fig. (24): Electron micrograph of the pancreas of Labeo niloticus showing the light and dark acinar cells, acinar lumen (arrow head) and secretory granules, which give an evidence for the process of exocytosis (stars).

Fig. (25): Electron micrograph of the pancreatic duct of Labeo niloticus showing the duct cells, nucleus, desmosomes, mitochondria and zymogenous secretion (star).

Fig. (26): Electron micrograph of the acinar cells of Labeo niloticus showing the nucleus, nucleolus, euchromatin, heterochromatin and nuclear envelope.

Ac.ce

Bi.ca

Bi.duc

Bl.sin

Bl.v

Cen.lu

Cen.ve

Cl.f

Com.con.tis

Con. tis.sep

Da.ac.ce

Da.h

Des

Duc.ce

Ec

End.ce

Gly.ro

$\mathrm{H}$

$\mathrm{Hc}$

I.ce

K.ce

Li.ac.ce

Li.h

Lp.dr

Ls

Mivi

\section{LIST OF ABBREVIATIONS}

Acinar cell.

Bile canaliculus.

Bile duct and bile ductule.

Blood sinusoid.

Blood vessel.

Central lumen.

Central vein.

Cord-like form.

Compact connective tissue.

Connective tissue septum.

Dark acinar cell.

Dark hepatocyte.

Desmosomes.

Duct cell.

Euchromatin.

Endothelial cell.

Glycogen rosettes.

Hepatocyte.

Heterochromatin.

Ito cell.

Kupffer cell.

Light acinar cell.

Light hepatocyte.

Lipid droplet.

Lysosomes.

Microvilli. 


$\begin{array}{ll}\mathrm{Mt} & \text { Mitochondria. } \\ \mathrm{N} & \text { Nucleus. } \\ \mathrm{N} . \mathrm{env} & \text { Nuclear envelope. } \\ \mathrm{Nu} & \text { Nucleolus. } \\ \text { p.ac } & \text { Pancreatic acini. } \\ \text { R.e.r } & \text { Rough endoplasmic reticulum. } \\ \text { Sec.gr } & \text { Secretory granules. } \\ \text { So.f } & \text { Solid form. } \\ \text { Sp.D } & \text { Space of Disse. } \\ \text { Tu.f } & \text { Tubular form. } \\ \text { Ves } & \text { Vesicles. } \\ \text { Z.gr } & \text { Zymogenous granules. }\end{array}$



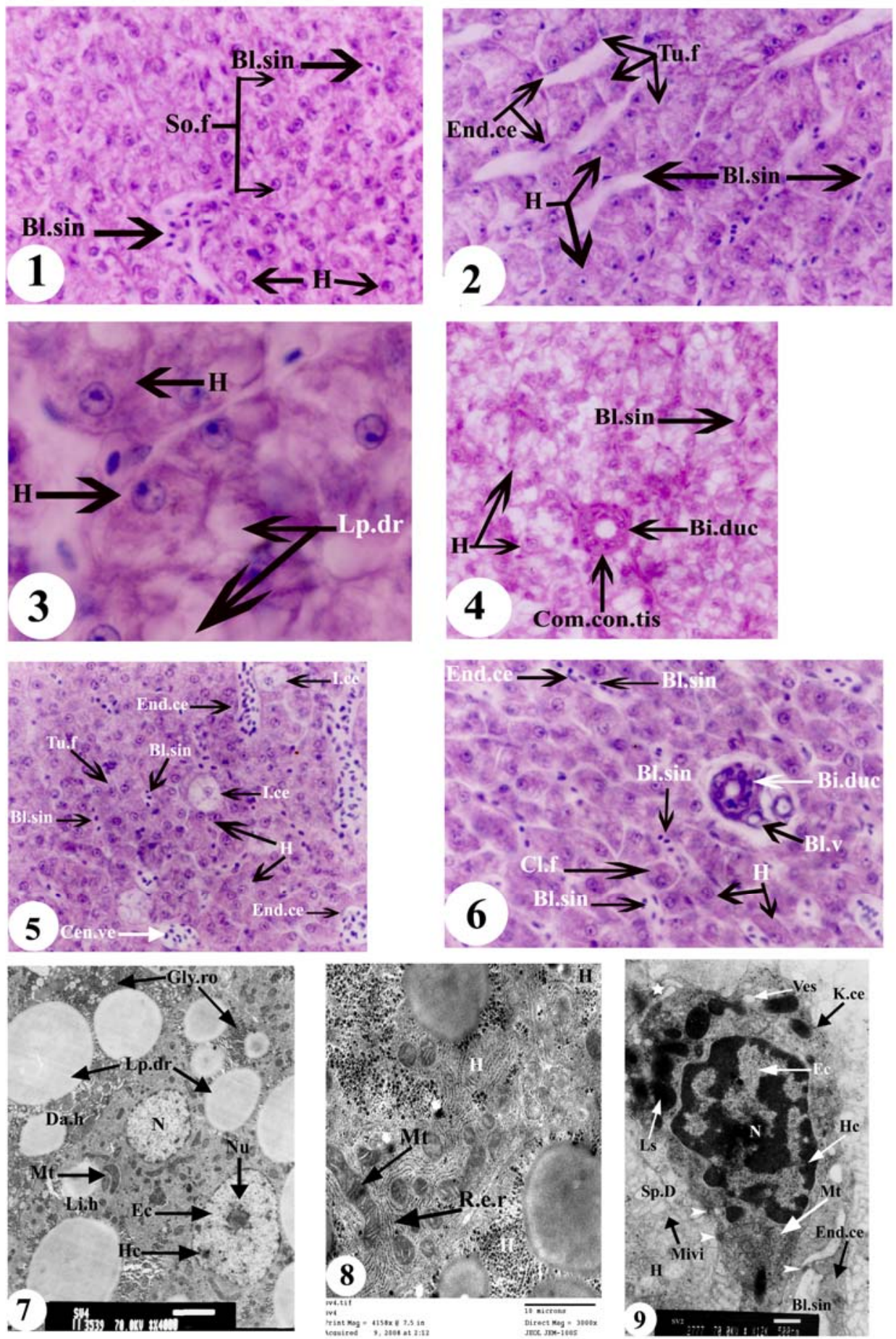

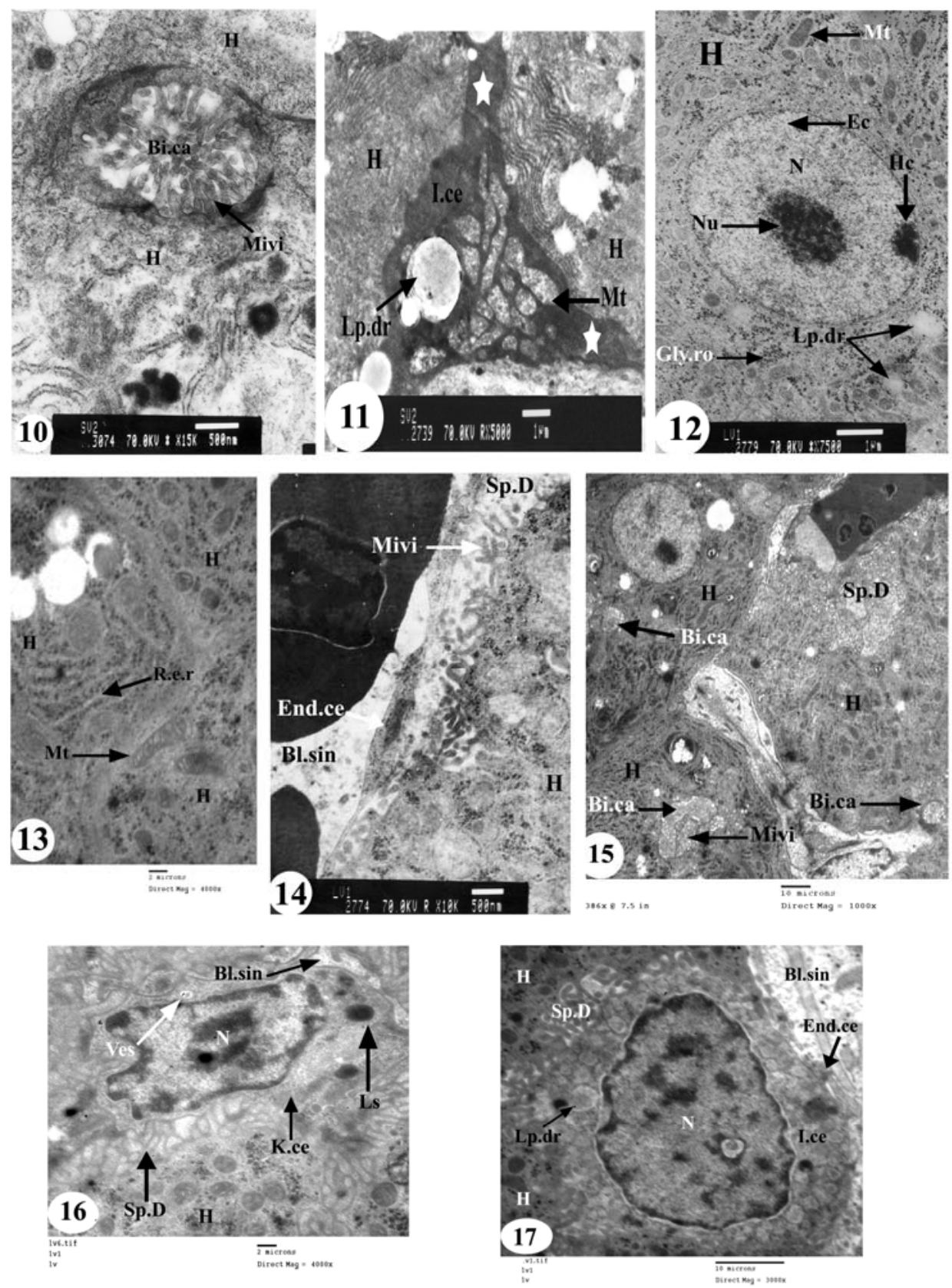

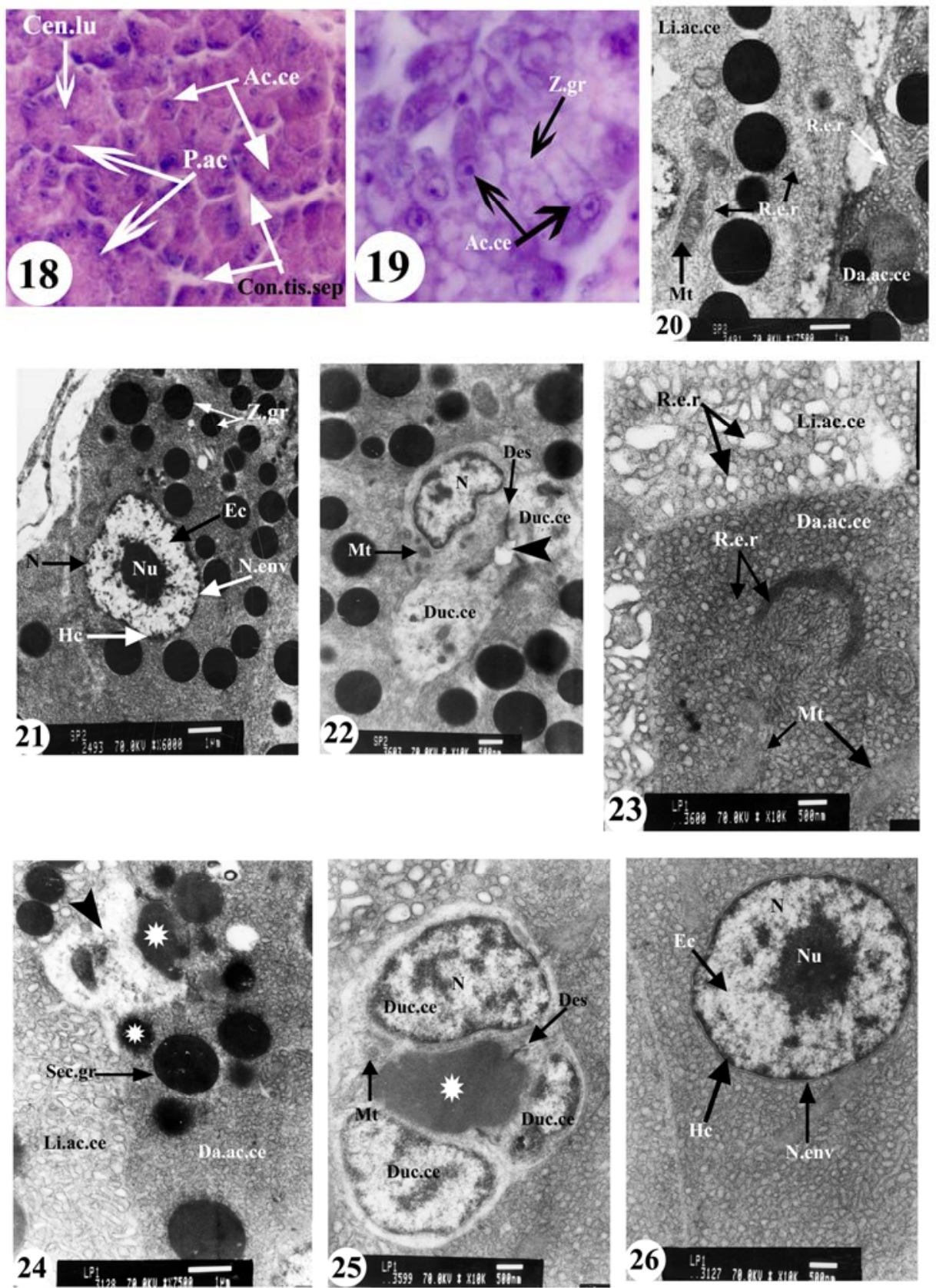

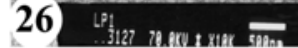

